\title{
A Hybrid Multiattribute Decision Making Model for Evaluating Students' Satisfaction towards Hostels
}

\author{
Anath Rau Krishnan, ${ }^{1}$ Engku Muhammad Nazri Engku Abu Bakar, \\ and Maznah Mat Kasim ${ }^{2}$ \\ ${ }^{1}$ Labuan Faculty of International Finance, Universiti Malaysia Sabah, 87000 Labuan, Sabah, Malaysia \\ ${ }^{2}$ Department of Decision Science, School of Quantitative Sciences, Universiti Utara Malaysia, 06010 Sintok, Kedah, Malaysia
}

Correspondence should be addressed to Anath Rau Krishnan; anath_85@yahoo.com

Received 18 October 2014; Accepted 13 April 2015

Academic Editor: Mahyar A. Amouzegar

Copyright (C) 2015 Anath Rau Krishnan et al. This is an open access article distributed under the Creative Commons Attribution License, which permits unrestricted use, distribution, and reproduction in any medium, provided the original work is properly cited.

\begin{abstract}
This paper proposes a new hybrid multiattribute decision making (MADM) model which deals with the interactions that usually exist between hostel attributes in the process of measuring the students' satisfaction towards a set of hostels and identifying the optimal strategies for enhancing their satisfaction. The model uses systematic random stratified sampling approach for data collection purpose as students dwelling in hostels are "naturally" clustered by block and gender, factor analysis for extracting large set of hostel attributes into fewer independent factors, $\lambda$-measure for characterizing the interactions shared by the attributes within each factor, Choquet integral for aggregating the interactive performance scores within each factor, Mikhailov's fuzzy analytical hierarchy process (MFAHP) for determining the weights of independent factors, and simple weighted average (SWA) operator to measure the overall satisfaction score of each hostel. A real evaluation involving fourteen Universiti Utara Malaysia (UUM) hostels was carried out in order to demonstrate the model's feasibility. The same evaluation was performed using an additive aggregation model in order to illustrate the effects of ignoring the interactions shared by attributes in hostel satisfaction analysis.
\end{abstract}

\section{Introduction}

These days, mushrooming number of universities forces each of them to try all the possible means to survive or win in the competitive marketplace. In the attempt to reflect themselves as the best place for pursuing tertiary education, certain universities are unceasingly putting effort in offering accommodations or hostels with satisfying quality as pleasing hostel condition always appears as one of the criteria for some students in choosing a university [1]. Apart as a strategy to attract large number of students, providing satisfying hostel life is also a key to encourage the students to be more engaged with the education environment [2] and thus could drive them for better academic performance $[3,4]$. Besides, the students who are satisfied with their hostels express higher sense of attachment and tend to further their studies in the same intuition. In nutshell, it is essential for the universities to timely identify and implement appropriate strategies in fulfilling the students' actual needs and enhance the students' satisfaction towards their hostels.

Unfortunately, identifying the optimal strategies is not a simple task as the degree of students satisfaction towards the hostels is normally influenced by multiple attributes. Following are some of the hostel attributes highlighted in past studies: number of roommates [5]; floor level [6]; recreation area, drain condition, and distance to clinic [7]; thermal comfort, indoor air quality, and furniture quality [8]; hostel maintenance, laundry [9]; internet facilities [10]; fees, room safety, and room size [11]; study room, ATM machine [12].

Besides, the review on past literature discloses that there is only minimal number of quantitative approaches that have been presented to this date in determining the optimal strategies for boosting the satisfaction towards a hostel. Most of the past studies (e.g., [11]) only employed factor analysis to discover the factors that influence the students' satisfaction but the tool alone failed to offer other types of essential 
information for the hostel administration (e.g., type of interactions between attributes and weights of the factors) in deciding efficient strategies. In addition, in several studies, the overall satisfaction score of each hostel under evaluation was simply computed by using the common arithmetic aggregator which presumes independency among attributes. However, in reality most of the attributes used for an assessment are interacted to each other [13]. The hostel attributes hold the same characteristic as well.

Hence, it is can be concluded that there is a need for a quantitative model which mainly deals with or considers the interactions between attributes in the process of evaluating the performance of a set of hostels based on students' satisfaction, in order to implement more practical strategies in enhancing their satisfaction.

This paper is organized as follows. Firstly, the needs for enhancing students' satisfaction towards a hostel and the existing problems relating to hostel evaluation are elucidated. Secondly, a review on past literature focusing on the usage of Choquet integral and its associated $\lambda$-measure is presented. Thirdly, the proposed hybrid MADM model is introduced. Fourthly, the workability of the proposed model is demonstrated by conducting a real analysis involving fourteen University Utara Malaysia (UUM) hostels. The contributions of the paper and the potential future research are summarized in the final section.

\section{Aggregation Phase in MADM}

MADM refers to a process of selecting, ranking, or classifying a set of alternatives based on varied, usually conflicting, attributes [14]. Applying multiple attribute utility theory (MAUT) techniques appears as a well-accepted standard, quantitative means for modeling MADM problems [15]. There are only three basic phases in implementing any of the MAUT techniques [16]. In the first phase, all the pertinent attributes for evaluating the alternatives under consideration are identified. The core components of a typical MAUT model are comprised of a set of $m$ alternatives denoted by $A=\left\{a_{1}, a_{2}, \ldots, a_{m}\right\}$ and a set of $n$ attributes represented by $C=\left\{c_{1}, c_{2}, \ldots, c_{n}\right\}$. In the following phase, the weights of attributes and performance score of each alternative with respect to each attribute are derived where some judgments or preference values from the experts or respondents are usually required for this purpose [17]. In the final phase, a specific function, namely, aggregation operator, is used to compose the set of weights and performance scores of each alternative into a single global score [18]. Based on these global scores, the alternatives can be then ranked up, classified, or selected where an alternative with highest global score signifies the most preferred alternative for the evaluation problem.

2.1. Aggregation Based on Choquet Integral. Normally, additive operators such as SWA which assume independency between attributes [19] are simply employed for the aggregation purpose. Unfortunately, this assumption is completely irrelevant to real scenario where in many cases, the attributes hold interactive characteristics $[13,20]$. Therefore, aggregation should not be always performed via additive aggregators as they failed to model the interactions between attributes $[21,22]$. However, with the aid of Choquet integral operator [23], the interactions between attributes can be captured during aggregation $[24,25]$. The usage of Choquet integral requires a prior identification of monotone measure weights, $g$. These weights represent not only the importance of each attribute but also the importance of all possible combinations or subsets of attributes [26-28]. As a result, for a MADM problem comprising $n$ number of attributes, $2^{n}$ number of weights needs to be identified prior to employing Choquet integral $[29,30]$.

$\lambda$-measure which was introduced by Sugeno [31] appears as one of the broadly used monotone measures due to its ease of usage, mathematical soundness, and modest degree of freedom characteristics [32]. Let $C=\left(c_{1}, c_{2}, \ldots, c_{n}\right)$ be a finite set. A set function $g_{\lambda}(\cdot)$ defined on the set of the subsets of $C, P(C)$, is called a $\lambda$-measure if it meets the following conditions:

(a) $g_{\lambda}: P(C) \rightarrow[0,1]$, and $g_{\lambda}(\emptyset)=0, g_{\lambda}(C)=1$ (boundary condition);

(b) $\forall A, B \in P(C)$, if $A \subseteq B$, then implies $g_{\lambda}(A) \leq g_{\lambda}(B)$ (monotonic condition);

(c) $g_{\lambda}(A \cup B)=g_{\lambda}(A)+g_{\lambda}(B)+\lambda g_{\lambda}(A) g_{\lambda}(B)$, for all $A, B \in P(C)$ where $A \cap B=\emptyset$ and $\lambda \in[-1,+\infty]$.

According to $[33,34]$, consider the following.

(a) If $\lambda<0$ then it implies that the attributes are sharing subadditive (redundancy) effects. This means a significant increase in the performance of the target can be achieved by only enhancing some attributes in $C$ which have higher individual weights.

(b) If $\lambda>0$ then it interprets that the attributes are sharing superadditive (synergy support) effects. This means a significant increase in the performance of the target can be achieved by simultaneously enhancing all the attributes in $C$ regardless of their individual weights.

(c) If $\lambda=0$ then it indicates that the attributes are noninteractive.

As $C=c_{j}=\left\{c_{1}, c_{2}, \ldots, c_{n}\right\}$ is finite, the entire $\lambda$-measure weights can be identified using

$$
\begin{aligned}
& g_{\lambda}\left\{c_{1}, c_{2}, \ldots, c_{n}\right\}=\frac{1}{\lambda}\left|\prod_{j=1}^{n}\left(1+\lambda g_{j}\right)-1\right|, \\
& \text { for }-1<\lambda<+\infty
\end{aligned}
$$

where $g_{j}=g_{\lambda}\left(c_{j}\right), j=1, \ldots, n$ denotes the individual weights of attributes. If $\sum_{j=1}^{n} g_{j}=1, \lambda=0$ whereas if $\sum_{j=1}^{n} g_{j} \neq 1$, the value of $\lambda$ can be identified by solving

$$
1+\lambda=\prod_{j=1}^{n}\left(1+\lambda g_{j}\right)
$$


The identified $\lambda$-measure weights and the available performance scores can be then swapped into Choquet integral model to compute the global score of each alternative. Let $g_{\lambda}$ be a monotone measure on $C=\left(c_{1}, c_{2}, \ldots, c_{n}\right)$ and let $X=$ $\left(x_{1}, x_{2}, \ldots, x_{n}\right)$ be the performance score of an alternative with respect to each attribute in $C$. Suppose $x_{1} \geq x_{2} \geq$ $\cdots \geq x_{n}$. Then, $T_{n}=\left(c_{1}, c_{2}, \ldots, c_{n}\right)$ and the aggregated score using Choquet integral can be determined using the following equation [35]:

$$
\begin{aligned}
& \text { Choquet }_{g_{\lambda}}\left(x_{1}, x_{2}, \ldots, x_{n}\right) \\
& =x_{n} \cdot g_{\lambda}\left(T_{n}\right)+\left[x_{n-1}-x_{n}\right] \cdot g_{\lambda}\left(T_{n-1}\right)+\cdots \\
& \quad+\left[x_{1}-x_{2}\right] \cdot g_{\lambda}\left(T_{1}\right) \\
& =x_{n} \cdot g_{\lambda}\left(c_{1}, c_{2}, \ldots, c_{n}\right)+\left[x_{n-1}-x_{n}\right] \\
& \quad \cdot g_{\lambda}\left(c_{1}, c_{2}, \ldots, c_{n-1}\right)+\cdots+\left[x_{1}-x_{2}\right] \cdot g_{\lambda}\left(c_{1}\right),
\end{aligned}
$$

where $T_{n}$ relies on the performance score with respect to each attribute. For better understanding, assume that the scores of a student, $x$ in three subjects (attributes), Mathematics $\left(x_{M}\right)$, Physics $\left(x_{P}\right)$, Literature $\left(x_{L}\right)$, are 75,80 , and 50 respectively. Since $x_{P} \geq x_{M} \geq x_{L}, T_{n}=(P, M, L)$ and the aggregated score of the student using Choquet integral, Choquet $_{g_{\lambda}}\left(x_{M}, x_{P}, x_{L}\right)=x_{L} \cdot g_{\lambda}(P, M, L)+\left(x_{M}-x_{L}\right)$. $g_{\lambda}(P, M)+\left(x_{P}-x_{M}\right) \cdot g_{\lambda}(P)$.

\section{Methodology}

The steps for executing the proposed hybrid model can be summarized as follows.

3.1. Identification of Attributes. In the first stage, a set of relevant attributes to assess the hostels under consideration are identified. Omitting any important attributes could lead to misleading decision.

3.2. Data Collection Using Systematic Random Stratified Sampling Approach. In the second stage, a questionnaire is designed based on the predetermined attributes as an instrument to collect the required data for the evaluation. Through the questionnaire, the selected students (respondents) are requested to express their satisfaction on each attribute with respect to their hostels and also to state their general views on the importance each attribute in determining a student's satisfaction, based on a preset Likert scale. Systematic random stratified sampling approach can be utilized in selecting the respondents for the survey purpose. According to [12], this sampling approach has been applied in many hostel evaluation studies as the students are usually or "naturally" grouped into groups, that is, by block and gender.

3.3. Deriving Decision Matrix (Hostels versus Attributes). In the third stage, the decision matrix of the evaluation problem which shows the performance score of each hostel with respect to each attribute is derived. The performance score of a hostel $i$ with respect to an attribute $j$ can be identified by averaging the satisfaction scores given by the students from hostel $i$.
3.4. Factor Analyzing the Data on the Importance of Attributes. In the fourth stage, the large dataset on the importance of attributes is used to perform factor analysis in order to extract the large set of attributes into fewer independent factors.

3.5. Constructing Simpler Hierarchal Evaluation System. By adhering to the result of factor analysis, the complex hostel evaluation problem is decomposed into a simpler hierarchical structure which depicts the goal of the evaluation, the factors which independently contributes to the actualization of the goal, and the interacted attributes within each factor together with the hostels' performance scores extracted from the derived decision matrix, in order to conduct the analysis in an organized means with better understanding.

3.6. Identification of Monotone Measure Weights. Since the attributes within each factor are being interactive, Choquet integral can be then employed in order to aggregate the performance scores within each factor. However, before applying Choquet integral, the $\lambda$-measure weights need to be identified. The identification process can be simplified as follows.

Firstly, the experts are required to express the individual importance or contribution of each attribute towards its corresponding factor in linguistic terms. Based on these terms, one of the eight fuzzy conversion scales as suggested by Chen and Hwang [36] is selected in order to quantify the linguistic terms into their respective fuzzy numbers. Further details on the principle of selecting the best scale can be found in [36]. Then, the corresponding crisp values for each of these fuzzy values are identified using a fuzzy scoring method as suggested in [36]. Subsequently, the final individual importance $\bar{I}_{j p}$ of an attribute $j$ corresponding to factor $p$ can be determined using

$$
\bar{I}_{j p}=\frac{1}{z} \sum_{e=1}^{z} I_{j_{e} p} .
$$

Suppose $E_{e}=\left\{E_{1}, E_{2}, \ldots, E_{z}\right\}$ represents the experts involved in the analysis; then, based on (4), $I_{j_{e} p}$ denotes the crisp importance of attribute $j$ with respect to factor $p$ that is derived from expert $e$ and $z$ implies the total number of experts involved. These final values actually represent the individual weights of attributes, $g_{j}=g_{\lambda}\left(c_{j}\right), j=1,2, \ldots, n$. Equations (2) and (1) can be then applied in order to find the interaction parameter, $\lambda$ and $\lambda$-measure weights of each factor.

3.7. Choquet Integral for Aggregating Interactive Scores. With the available $\lambda$-measure weights, Choquet integral model (3) can be then used to aggregate the interactive performance scores within each factor. As a result, by end of this step, each hostel will have an aggregated score with respect to each factor (in other words, each hostel will have a set of factor scores) and thus a new decision matrix (hostels versus factors) can be developed for further analysis.

3.8. Using MFAHP for Allocating Weights on Independent Factors. MFAHP [37] is used to identify the weights of independent factors due to its ability to capture the uncertainty 
TABLE 1: Fuzzy AHP scale.

\begin{tabular}{lcr}
\hline Linguistic terms & Corresponding TFNs & Descriptions \\
\hline Equally important & $\widetilde{1}=(1,1,2)$ & Two factors contribute equally \\
Slightly important & $\widetilde{3}=(2,3,4)$ & One factor is slightly favoured over another \\
Strongly important & $\widetilde{5}=(4,5,6)$ & One factor is strongly favoured over another \\
Very strongly important & $\widetilde{7}=(6,7,8)$ & One factor is very strongly favoured over another \\
Extremely important & $\widetilde{9}=(8,9,9)$ & One factor is most favoured over another \\
The intermediate values & $\widetilde{2}=(1,2,3), \widetilde{4}=(3,4,5), \widetilde{6}=(5,6,7), \widetilde{8}=(7,8,9)$ & Used to compromise between two judgments \\
\hline
\end{tabular}

that usually embedded in human's judgments and to derive the weights of the factors and consistency value of pairwise comparison matrix simultaneously by simply solving the nonlinear optimization model suggested in [37]. With respect to the proposed model, MFAHP can be executed as follows.

Firstly, after achieving consensus via Delphi method, the experts are required to linguistically express the mutually agreed judgments on the relative importance of the factors through a single pairwise matrix (for sake of simplicity) based on Saaty's fuzzy AHP scale as shown in Table 1. It has to be mentioned here that in order to avoid using reciprocal judgment (values between $\widetilde{9}^{-1}$ and $\widetilde{1}^{-1}$ ) which could lead to rank reversal problem, MFAHP only requires the experts to offer assessment whenever factor $f_{a}$ is equally or more important than $f_{b}$. If they consider that $f_{a}$ is less important than $f_{b}$ then the assessment should be done oppositely where $f_{b}$ is compared to $f_{b}$. It can be noticed that the reciprocal judgments are not offered in Table 1 as they are not required for using MFAHP.

Secondly, the linguistic terms in the assessed pairwise matrix are quantified into their corresponding triangular fuzzy numbers (TFNs). Finally, the suggested nonlinear optimization model (5) can be constructed based on the fuzzy pairwise matrix and solved with the aid of EXCEL Solver to derive the consistency value of the matrix and the weights of the factors:

$$
\begin{array}{cl}
\text { Maximize } & \mu \\
\text { Subject to; } & \left(m_{a b}-l_{a b}\right) \mu w_{b}-w_{a}+l_{a b} w_{b} \leq 0 \\
& \left(u_{a b}-m_{a b}\right) \mu w_{b}+w_{a}-u_{a b} w_{b} \leq 0 \\
& \sum_{p=1}^{q} w_{p}=1, \quad w_{p}>0, p=1, \ldots, q .
\end{array}
$$

With regard to the proposed model, $l_{a b}, u_{a b}$, and $u_{a b}$ represent the lower, upper, and most probable values corresponding to the fuzzy judgment given by the experts when comparing factor $f_{a}$ to $f_{b}$. Meanwhile, $w_{p}$ denotes the weight of factor $f_{p}$ and $\mu$ represents the consistency index of the pairwise comparison. Positive $\mu$ value indicates that the fuzzy pairwise comparison matrix is being consistent. If the value is negative then it implies that the comparison matrix is being inconsistent and reevaluation on the pairwise comparison is required.
3.9. SWA Operator for Aggregating Independent Factor Scores. With the identified weights of factors, the independent factor scores can be then aggregated using SWA operator (6) in order to compute the overall satisfaction score of each hostel:

$$
\sum_{p=1}^{q}\left(w_{p} \cdot y_{p}\right)
$$

where $w_{p}$ implies the weight of factor $p$ and $y_{p}$ represents the score of a hostel with respect to factor $p$. The hostels can be then ranked in a descending order based on their overall scores. The result or information derived through the model can be utilized by each hostel administration to develop the optimal strategies for enhancing the students' satisfaction towards their respective hostels.

\section{Real Application}

Universiti Utara Malaysia (UUM) offers accommodation for nearly 22,000 students through its fifteen hostels which are named after multinational companies: MAS, TNB, Tradewinds, Proton, Petronas, EON, Sime Darby, MISC, TM, Perwaja, Bank Muamalat, YAB, Bank Rakyat, SME, and Maybank. The accommodation is provided for all the undergraduate students ranging from first to final semester and the postgraduate students are allowed to stay upon the approval of the authorized unit. In the attempt to test the feasibility of the proposed model, this paper has focused on evaluating and suggesting the strategies to improve the students' satisfaction towards fourteen UUM hostels. Maybank hostel which is specially designed for married students was excluded from the evaluation to minimize biasness as it has different standard of facilities, management, and service.

4.1. Hostel Attributes for Evaluation. Through the participation of five panels of experts who are familiar with UUM's hostels management in a series of brainstorming sessions, 22 attributes as listed in Table 2 were finalized for the evaluation purpose.

4.2. Data Collection. The questionnaire designed for the data collection process was divided into two main sections: first section to let the respondents to specify their level of satisfaction on each attribute with respect to their own hostel and second section to let the respondents to indicate their 
TABLE 2: List of hostel attributes.

\begin{tabular}{|c|c|c|}
\hline Number & Attributes & Descriptions \\
\hline 1 & Hostel's exterior & Attractive landscape and exterior design \\
\hline 2 & Distance to university facilities & $\begin{array}{l}\text { Distance to university facilities such as library, post office, book store, bank, mini } \\
\text { market, and sports complex }\end{array}$ \\
\hline 3 & Bus & Frequent and prompt bus service, hospitable driver \\
\hline 4 & Room population & The room is not too crowded \\
\hline 5 & Security system & Effectiveness of security guard and availability of CCTV surveillance \\
\hline 6 & Safety & $\begin{array}{l}\text { Availability and condition of fire extinguishers, smoke detectors, and handrails for } \\
\text { stairs }\end{array}$ \\
\hline 7 & Room size & Room is spacious \\
\hline 8 & Fees & Fees per semester is reasonable, value for money \\
\hline 9 & Cafeteria & $\begin{array}{l}\text { Fresh, hygienic, variety of food with reasonable price, cleanliness of cafeteria and so } \\
\text { forth }\end{array}$ \\
\hline 10 & Maintenance service & $\begin{array}{l}\text { The defect facilities and equipment in room are fixed promptly after the complaint } \\
\text { is made/effectiveness of service }\end{array}$ \\
\hline 11 & Cleaning service & The cleanliness level of toilets, corridors, exterior of building are well maintained \\
\hline 12 & Physical condition of room & Ventilation, lighting, furniture, and painting \\
\hline 13 & Wi-Fi accessibility & Good Wi-Fi connection, accessible everywhere within the hostel \\
\hline 14 & Computer lab facility & $\begin{array}{l}\text { Organized, computers are in good condition, availability of printing service and so } \\
\text { forth }\end{array}$ \\
\hline 15 & Study room facility & Quite, clean, encouraging environment to study and so forth \\
\hline 16 & Accessibility to ATM & Easy to get to the nearest ATM \\
\hline 17 & TV facility & Quality of TV, number of TVs available, availability of ASTRO channel packages \\
\hline 18 & Laundry facility & $\begin{array}{l}\text { Laundry room and washing machines in good condition, suitable and enough space } \\
\text { to dry up laundry, and so forth }\end{array}$ \\
\hline 19 & Sports facility & $\begin{array}{l}\text { Variety of sports facilities within hostel, good condition of futsal/netball court/other } \\
\text { sports facilities within hostel }\end{array}$ \\
\hline 20 & Management & Satisfaction with principal, fellows, and administrative staff services \\
\hline 21 & Washrooms and toilets & $\begin{array}{l}\text { Well-equipped, privacy is secured, sufficient numbers of toilets, spacious and } \\
\text { comfortable toilets }\end{array}$ \\
\hline 22 & Students representative committee (SRC) & $\begin{array}{l}\text { SRC really conscious about students' problems and needs, organizing valuable and } \\
\text { interesting programs for students throughout the semester }\end{array}$ \\
\hline
\end{tabular}

general views on the importance of each hostel attribute for a student. Prior to conducting the actual survey, the questionnaire was pretested with a small group of students and based on their feedbacks, some alterations were made on the questionnaire; especially some puzzling terms were replaced with straightforward words. The actual data collection process was then conducted using the revised version of the questionnaire.

The respondents from each hostel were selected using a systematic random stratified sampling approach; the students living in each hostel were naturally clustered by block and gender. The respondents from each "cluster" or block were then selected by using a systematic random sampling approach where the students residing in every forth room in the block were chosen for the survey purpose after randomly selecting the first room at the first floor.

As a cautionary measure, during survey the actual purpose of the survey which was to evaluate the satisfaction towards 14 residential halls was kept confidential as they could offer biased judgment due to the sense of attachment factor. Therefore, the respondents were simply informed that the purpose of the survey was just to analyze and enhance the current condition of the particular hostel. Besides, prior to offering the questionnaire, a screening question was asked to the respondents to ensure they are really staying in the hostel and not there for visiting or other reasons. We assisted the respondents throughout the answering process and assured that the questionnaires were fulfilled completely. The survey was scheduled and conducted after $5 \mathrm{pm}$ as most of the students would be free from classes or any other campus activities after this point of time. The survey took almost three weeks to be accomplished with the help of two male and female postgraduate students.

4.3. Decision Matrix (Hostels versus Attributes). By averaging the scores given by the students from each hostel with respect to each attribute, the decision matrix as shown in Table 3 was derived. 
TABLE 3: Hostels versus attributes.

\begin{tabular}{|c|c|c|c|c|c|c|c|c|c|c|c|}
\hline & Exterior & Distance & Bus & Population & Security & Safety & Size & Fees & Cafeteria & Maintenance & Cleaning \\
\hline $\mathrm{BR}^{1}$ & 5.549 & 4.703 & 3.773 & 7.043 & 4.673 & 5.685 & 6.255 & 4.830 & 3.045 & 4.890 & 5.475 \\
\hline SME & 5.415 & 4.575 & 4.620 & 7.230 & 5.303 & 6.255 & 6.923 & 5.340 & 5.497 & 6.098 & 5.445 \\
\hline $\mathrm{SD}^{2}$ & 5.573 & 5.865 & 4.763 & 6.570 & 4.110 & 5.618 & 5.610 & 4.822 & 3.000 & 4.560 & 4.350 \\
\hline $\mathrm{EON}$ & 5.475 & 5.640 & 4.928 & 6.690 & 4.095 & 5.100 & 5.587 & 5.115 & 4.995 & 5.092 & 5.227 \\
\hline $\mathrm{MT}^{3}$ & 5.175 & 5.535 & 5.978 & 4.800 & 3.998 & 4.710 & 3.855 & 4.163 & 4.912 & 4.845 & 4.703 \\
\hline YAB & 5.018 & 4.785 & 5.325 & 5.873 & 3.915 & 4.673 & 5.250 & 4.800 & 4.350 & 4.372 & 5.310 \\
\hline $\mathrm{PR}^{4}$ & 4.793 & 5.888 & 3.675 & 6.555 & 3.735 & 4.950 & 5.483 & 4.658 & 4.500 & 4.613 & 3.885 \\
\hline MAS & 5.280 & 4.965 & 4.718 & 6.915 & 4.493 & 5.213 & 6.540 & 4.912 & 3.893 & 4.642 & 3.975 \\
\hline $\mathrm{PS}^{5}$ & 5.663 & 6.930 & 4.305 & 6.615 & 4.673 & 5.460 & 5.490 & 4.830 & 4.800 & 4.838 & 4.860 \\
\hline TNB & 5.078 & 5.790 & 4.140 & 6.473 & 4.583 & 5.445 & 5.873 & 5.415 & 4.793 & 5.423 & 4.433 \\
\hline $\mathrm{TS}^{6}$ & 4.590 & 6.015 & 4.237 & 6.068 & 3.420 & 4.687 & 5.205 & 4.230 & 3.795 & 4.395 & 4.793 \\
\hline $\mathrm{PJ}^{7}$ & 5.258 & 5.940 & 5.670 & 7.297 & 3.818 & 5.933 & 5.955 & 5.108 & 6.262 & 5.213 & 5.820 \\
\hline MISC & 5.565 & 4.935 & 5.385 & 6.923 & 3.427 & 4.860 & 5.820 & 5.055 & 5.047 & 4.815 & 5.325 \\
\hline \multirow[t]{2}{*}{$\mathrm{TM}$} & 4.905 & 5.040 & 5.587 & 7.425 & 3.922 & 4.957 & 5.925 & 4.815 & 2.970 & 4.875 & 5.430 \\
\hline & Physical & $\mathrm{Wi}-\mathrm{Fi}$ & $\mathrm{Lab}$ & Study room & ATM & TV & Laundry & Sports & Management & Washroom & SRC \\
\hline $\mathrm{BR}^{1}$ & 5.783 & 3.112 & 5.775 & 4.838 & 6.180 & 4.020 & 3.915 & 5.303 & 5.243 & 5.175 & 4.192 \\
\hline SME & 6.885 & 3.495 & 5.767 & 5.295 & 5.288 & 3.060 & 3.945 & 5.573 & 5.430 & 5.632 & 4.687 \\
\hline $\mathrm{SD}^{2}$ & 5.985 & 4.620 & 5.775 & 3.795 & 4.133 & 3.150 & 2.985 & 4.350 & 4.860 & 4.088 & 4.755 \\
\hline $\mathrm{EON}$ & 5.902 & 5.670 & 5.947 & 4.448 & 4.763 & 3.975 & 4.455 & 5.295 & 5.722 & 4.785 & 5.258 \\
\hline $\mathrm{MT}^{3}$ & 4.845 & 3.720 & 5.835 & 3.930 & 6.120 & 3.975 & 4.343 & 4.890 & 4.898 & 4.912 & 4.703 \\
\hline YAB & 5.452 & 4.410 & 4.343 & 4.433 & 5.168 & 3.368 & 4.597 & 5.168 & 5.344 & 4.950 & 5.520 \\
\hline $\mathrm{PR}^{4}$ & 6.233 & 4.695 & 5.722 & 4.673 & 4.230 & 3.848 & 4.613 & 4.095 & 4.275 & 3.195 & 3.713 \\
\hline MAS & 5.677 & 5.685 & 6.248 & 4.358 & 3.015 & 2.310 & 4.065 & 3.825 & 4.725 & 4.035 & 4.313 \\
\hline $\mathrm{PS}^{5}$ & 6.098 & 5.640 & 6.675 & 4.822 & 6.518 & 5.565 & 5.670 & 5.182 & 5.085 & 5.198 & 5.205 \\
\hline TNB & 5.925 & 5.063 & 5.745 & 4.650 & 4.035 & 2.685 & 3.495 & 3.870 & 4.710 & 3.900 & 4.335 \\
\hline $\mathrm{TS}^{6}$ & 5.992 & 4.770 & 5.317 & 4.845 & 5.213 & 5.280 & 4.845 & 4.905 & 5.130 & 4.875 & 4.763 \\
\hline $\mathrm{PJ}^{7}$ & 6.615 & 5.550 & 6.383 & 4.440 & 2.797 & 4.020 & 4.350 & 4.440 & 5.055 & 4.568 & 4.943 \\
\hline MISC & 5.288 & 4.793 & 6.105 & 3.472 & 2.250 & 2.895 & 3.112 & 3.945 & 4.133 & 3.533 & 5.303 \\
\hline TM & 6.503 & 5.632 & 6.622 & 4.620 & 2.880 & 3.713 & 4.425 & 4.057 & 4.620 & 4.530 & 5.280 \\
\hline
\end{tabular}

${ }^{1} \mathrm{BR}=$ Bank Rakyat, ${ }^{2} \mathrm{SD}=$ Sime Darby, ${ }^{3} \mathrm{MT}=$ Muamalat,${ }^{4} \mathrm{PR}=$ Proton, ${ }^{5} \mathrm{PS}=$ Petronas, ${ }^{6} \mathrm{TS}=$ Tradewinds, and ${ }^{7} \mathrm{PJ}=$ Perwaja.

4.4. Conducting Factor Analysis. Before factor analyzing the large dataset on the importance of attributes obtained through the second section of the questionnaire, the suitability of the data for factor analysis was verified with the aid of SPSS software. The inspection on the correlation matrix revealed the presence of many coefficients of 0.3 and above. Besides, the Kaiser-Meyer-Olkin (KMO) value of the dataset exceeded the recommended value, 0.6, and Bartlett's Test of Sphericity reached statistical significance as the $p$ value was less than 0.05 . These three circumstances indicated that the dataset was suitable for factor analysis.

By performing factor analysis, the large set of hostel attributes was clustered into five independent factors. However, it has to be emphasized that the attributes within each extracted factor are still interacted to each other. The result of factor analysis for this study can be further detailed as follows (refer to Table 4). Extraction through principal component analysis revealed the presence of five common factors with eigenvalues exceeding one, explaining 30.014\%, 8.487\%,
$5.667 \%, 5.522 \%$, and $5.291 \%$ of the variance, respectively. The total variance explained reached $54.982 \%$. To aid in the interpretation of these five common factors, varimax rotation was performed.

Five attributes, "cleaning," "washrooms," "maintenance," "management," and "SRC," which had higher loading at factor 1 , were renamed as service factor $\left(f_{1}\right)$. Meanwhile, "TV," "laundry," "ATM," "sports," and "study room" which showed higher loading at factor 2 were relabeled as "facility" factor $\left(f_{2}\right)$. "Population," "size," "physical," "lab," and "Wi-Fi" which were clustered into factor 3 were identified as convenience factor $\left(f_{3}\right)$ and "bus," "distance," "cafeteria," "exterior," and "fees" were classified as value for money factor $\left(f_{4}\right)$. Finally, "security" and "safety" which had higher loading at factor 5 were renamed as precaution factor $\left(f_{5}\right)$.

4.5. Hierarchical Evaluation System for Analyzing UUM Hostels. Table 5 is hierarchical structure constructed based on the result of factor analysis used to systematically evaluate 
TABLE 4: Result of factor analysis.

\begin{tabular}{|c|c|c|c|c|c|c|c|c|c|}
\hline & Tota & iance explained & & & otated & apones & atrix & & \\
\hline Component & & Initial eigen & & Attributes & & & mpon & & \\
\hline 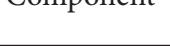 & Total & $\%$ of variance & Cumulative \% & 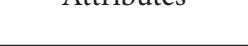 & 1 & 2 & 3 & 4 & 5 \\
\hline 1 & 6.603 & 30.014 & 30.014 & Cleaning $\left(c_{11}\right)$ & .749 & & & & \\
\hline 2 & 1.867 & 8.487 & 38.501 & Washroom $\left(c_{21}\right)$ & .717 & .379 & & & \\
\hline 3 & 1.247 & 5.667 & 44.169 & Maintenance $\left(c_{10}\right)$ & .612 & & & & \\
\hline 4 & 1.215 & 5.522 & 49.691 & Management $\left(c_{20}\right)$ & .602 & .341 & & & \\
\hline 5 & 1.164 & 5.291 & 54.982 & $\operatorname{SRC}\left(c_{22}\right)$ & .527 & & & & \\
\hline 6 & .929 & 4.222 & 59.204 & $\operatorname{TV}\left(c_{17}\right)$ & & .786 & & & \\
\hline 7 & .871 & 3.961 & 63.166 & Laundry $\left(c_{18}\right)$ & & .723 & & & \\
\hline 8 & .777 & 3.530 & 66.696 & $\operatorname{ATM}\left(c_{16}\right)$ & & .665 & & & \\
\hline 9 & .768 & 3.489 & 70.184 & Sports $\left(c_{19}\right)$ & & .638 & & & \\
\hline 10 & .710 & 3.225 & 73.410 & Study room $\left(c_{15}\right)$ & & .435 & & & .346 \\
\hline 11 & .649 & 2.949 & 76.359 & Population $\left(c_{4}\right)$ & & & .673 & & \\
\hline 12 & .594 & 2.701 & 79.060 & Size $\left(c_{7}\right)$ & & & .647 & & .412 \\
\hline 13 & .582 & 2.644 & 81.704 & Physical $\left(c_{12}\right)$ & .409 & & .583 & & \\
\hline 14 & .570 & 2.591 & 84.295 & $\operatorname{Lab}\left(c_{14}\right)$ & & & .561 & .412 & \\
\hline 15 & .515 & 2.339 & 86.635 & $\mathrm{Wi}-\mathrm{Fi}\left(c_{13}\right)$ & & & .547 & .427 & \\
\hline 16 & .490 & 2.229 & 88.864 & Bus $\left(c_{3}\right)$ & .307 & & & .650 & \\
\hline 17 & .476 & 2.163 & 91.027 & Distance $\left(c_{2}\right)$ & & .329 & & .649 & \\
\hline 18 & .458 & 2.082 & 93.109 & Cafeteria $\left(c_{9}\right)$ & .449 & & & .453 & \\
\hline 19 & .427 & 1.941 & 95.050 & Exterior $\left(c_{1}\right)$ & & & & .453 & .448 \\
\hline 20 & .391 & 1.779 & 96.829 & Fees $\left(c_{8}\right)$ & & & .355 & .391 & \\
\hline 21 & .375 & 1.705 & 98.535 & Security $\left(c_{5}\right)$ & & & & & .756 \\
\hline 22 & .322 & 1.465 & 100.000 & Safety $\left(c_{6}\right)$ & & & & & .684 \\
\hline
\end{tabular}

the students' satisfaction towards the 14 hostels. It has to be emphasized that Table 5 exemplifies that the attributes within each factor are interacted to each other whereas the factors are playing independent roles in determining the students' overall satisfaction.

4.6. Identification of $\lambda$-Measure Weights. Based on the judgements from the experts, the 11-point scale, as shown in Table 6 , was chosen to aid the process of identifying the individual weights of attributes. The Identification of aggregated or final individual weights of the attributes within each factor based on the judgements from the five experts is summarized in Table 7.

With the available individual weights, (2) and (3) were then used in order to obtain the interaction parameter, $\lambda$, and monotone measure weights of each factor as presented in Table 8.

Through the proposed model, by extracting the attributes into fewer independent factors, the actual number of monotone measure weights which need to be identified prior to applying Choquet integral was reduced from 4194304 $\left(2^{13}\right)$ weights to $132\left(2^{5}+2^{5}+2^{5}+2^{5}+2^{2}\right)$ weights. In general, the proposed model reduces the required number of monotone measure weights from $2^{n}$ to $\sum_{p=1}^{q} 2^{\left|f_{p}\right|}$ where $f_{p}=\left(f_{1}, f_{1}, \ldots, f_{q}\right)$ is the set of extracted factors, $q$ denotes the total number of factors, and $\left|f_{p}\right|$ represents the number of attributes within factor, $p$.

4.7. Aggregation Using Choquet Integral. By aggregating the interactive scores within each factor using the identified monotone measure and Choquet integral model (3), a new decision matrix (14 hostels versus 5 factors) as shown in Table 10 was attained.

4.8. Identifying the Weights of Independent Hostel Factors. After achieving consensus through Delphi method, the five experts have linguistically expressed their judgments on the relative importance of the hostel factors through a single pairwise matrix based. The linguistic pairwise matrix was then converted into fuzzy pairwise matrix as shown in Table 9 based on fuzzy AHP scale (refer to Table 1). It can be noticed that since the "value for money" was found to be less important than "precaution" factor, the evaluation was done vice versa to avoid using reciprocal values.

Based on the fuzzy pairwise comparison, the suggested nonlinear optimization model (5) was constructed and solved with the aid of EXCEL Solver. Following result was obtained: weight of service factor, $w_{1}=0.374$; weight of facility factor, $w_{2}=0.309$; weight of convenience factor, $w_{3}=0.147$; weight of value for money factor, $w_{4}=0.065$; weight of 


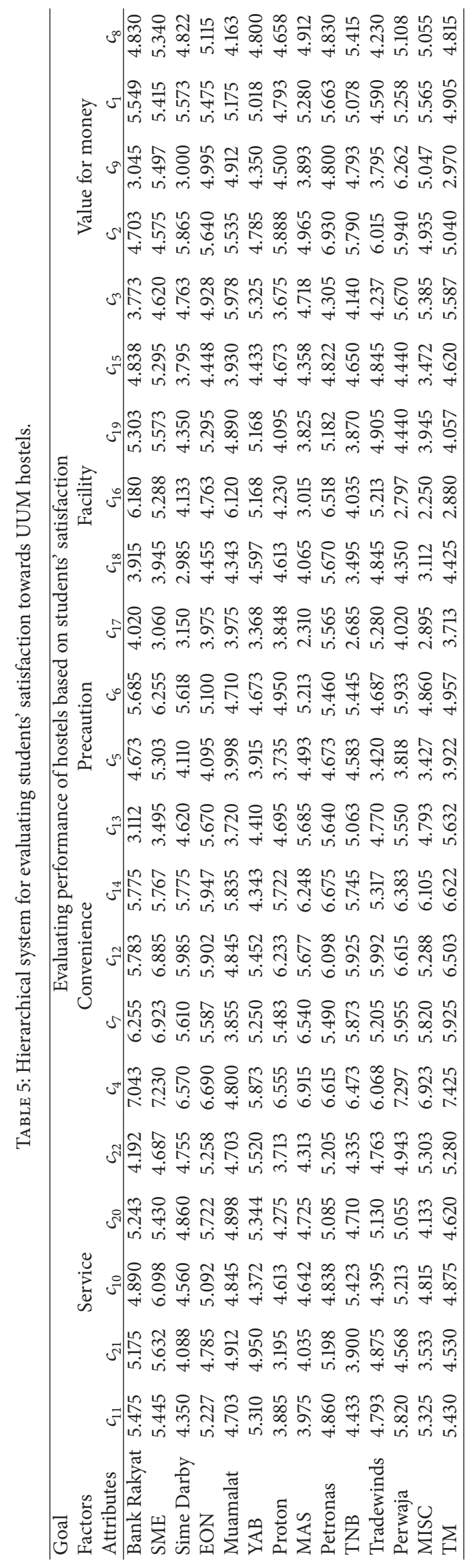


TABLE 6: 11-point linguistic scale for expressing individual importance of attributes.

\begin{tabular}{lcc}
\hline Linguistic terms & Fuzzy numbers & $\begin{array}{c}\text { Corresponding crisp } \\
\text { values identified via } \\
\text { fuzzy scoring } \\
\text { approach }\end{array}$ \\
\hline Exceptionally low (EL) & $(0,0,0.1)$ & 0.045 \\
Extremely low (ExL) & $(0,0.1,0.2)$ & 0.135 \\
Very low (VL) & $(0,0.1,0.3,0.5)$ & 0.255 \\
Low (L) & $(0.1,0.3,0.5)$ & 0.335 \\
Below average (BA) & $(0.3,0.4,0.5)$ & 0.410 \\
Average (A) & $(0.3,0.5,0.7)$ & 0.5 \\
Above average (AA) & $(0.5,0.6,0.7)$ & 0.590 \\
High (H) & $(0.5,0.7,0.9)$ & 0.665 \\
Very high (VH) & $(0.5,0.7,0.9,1)$ & 0.745 \\
Extremely high (ExH) & $(0.8,0.9,1)$ & 0.865 \\
Exceptionally high (EH) & $(0.9,1,1)$ & 0.955 \\
\hline
\end{tabular}

precaution factor, $w_{5}=0.106$; consistency index, $\mu=0.634$. The value of $\mu$ implied that the pairwise comparison matrix was consistent.

4.9. Aggregation Using SWA Operator. The identified weights of factors and available factor scores were precisely replaced into SWA model (6) to compute the overall satisfaction score of each hostel. The satisfaction score of each hostel and their ranking are summarized in Table 10.

\subsection{Proposed Hybrid MADM Model versus Classical SWA} Operator. In this section, the same hostel satisfaction problem was evaluated using a classical, additive aggregation operator or to be precise, by only employing the common SWA operator and the obtained result was compared with the result generated by the proposed model. The motive of choosing classical SWA was to mainly demonstrate the implication of discounting the interactions between attributes in hostel satisfaction analysis.

As SWA assumes independency between attributes, it is crucial to assure the sum of weights of the 22 attributes is being additive (or equal to one). To derive the weights for SWA, firstly, the nonadditive individual weights of attributes within each factor (refer to Table 7) were normalized to ensure the sum of the weights is equal to one. These normalized weights were just represented the contribution of attributes towards their respective factor. Hence, the final additive weight of each attribute (contribution of attributes towards overall satisfaction) was then computed by multiplying an attribute's normalized weight with the weight of its respective factor. Note that the weights of factors do not demand any normalization as they were already in the additive state. Table 11 recapitulates the process involved in determining the required additive weights of attributes for applying SWA operator.

The identified additive weights and the performance scores as presented in Table 3 were then swapped into
SWA model (6) to compute the overall satisfaction score of each hostel. Table 12 shows the disparities on the overall satisfaction scores and ranking of the hostels resulting from the proposed model and conventional SWA.

It can be concluded that there was a significant variation between the result generated through the proposed model and classical SWA as the latter model ignores the usual interactions that exist between hostel attributes. Besides, the additive weights used for SWA failed to express the interactions shared by the attributes and thus could lead to the implementation of inefficient satisfaction enhancement strategies.

4.11. Discussion on the Result. Through the proposed model, with the help of factor analysis, it was discovered that the actual determinants of the students' satisfaction towards the hostels are service, facility, convenience, value for money, and precaution aspects. However, it was understood that the prioritization on these determinants is as follows: service $(0.374)>$ facility $(0.309)>$ convenience $(0.147)>$ precaution $(0.106) \succ$ value for money $(0.065)$ where $>$ means "is preferred or superior to." Therefore, in order to enhance the students' satisfaction, a hostel can simply focus on the four crucial aspects; service, facility, convenience, and precaution aspects which are independent of each other.

The interaction parameter, $\lambda=-0.956$, indicates that in order to improve a hostel's performance in term of service, it is enough to simultaneously enhance some of the attributes which have higher individual weights; management and maintenance. In other words, by only enhancing management and maintenance attributes, a significant improvement in the aspect of service can be achieved. The experts involved in the analysis accepted this fact by stating that a good management and maintenance team can ensure the other attributes within the factor are being at the satisfactory level. According to them, a good management team often monitors the cleanliness level of the hostel and motivates the students' representative committee (SRC) to frequently organize fruitful activities for the students. Besides, a caring management and effective maintenance team timely ensure the washrooms and toilets are being in good condition.

Meanwhile, $\lambda=0.035$ implies that in order to improve a hostel's performance with respect to facility factor, all the attributes within the factor need to be enhanced simultaneously regardless of their individual weights; TV, laundry, ATM, sports amenities, and study room. The similar strategy applies for improving the precaution level of a hostel as it has a positive interaction parameter $(\lambda=0.140)$.

The value, $\lambda=-0.943$, shows that in order to attain drastic improvement in convenience aspect, it is sufficient to simultaneously enhance some of the attributes which have higher individual weights; physical condition of the room and Wi-Fi accessibility. According to the experts, a good furniture arrangement, ventilation, paint colours, and lighting have the capability to form spacious and comforting in-room environment even if the room is small (refers to "room size" attribute) or crowded (refers to "room population" attribute). Besides, in current trend of education which largely relies on internet facility, a fine Wi-Fi accessibility would enable 
TABLE 7: Identification of individual weights of attributes within each factor.

\begin{tabular}{|c|c|c|c|c|c|c|c|c|c|c|c|c|}
\hline \multirow[t]{2}{*}{ Factors } & \multirow[t]{2}{*}{ Criteria } & \multicolumn{5}{|c|}{$\begin{array}{l}\text { Degree of Importance } \\
\text { (in linguistic terms) }\end{array}$} & \multicolumn{5}{|c|}{$\begin{array}{l}\text { Importance } \\
\text { (in crisp values after defuzzyfying fuzzy numbers) }\end{array}$} & \multirow{2}{*}{$\begin{array}{c}\text { Aggregated } \\
\text { individual } \\
\text { weights }\end{array}$} \\
\hline & & $E_{1}$ & $E_{2}$ & $E_{3}$ & $E_{4}$ & $E_{5}$ & $E_{1}$ & $E_{2}$ & $E_{3}$ & $E_{4}$ & $E_{5}$ & \\
\hline \multirow{5}{*}{ Service } & Cleaning & $\mathrm{VH}$ & $\mathrm{AA}$ & $\mathrm{A}$ & $\mathrm{BA}$ & $\mathrm{A}$ & 0.745 & 0.59 & 0.5 & 0.41 & 0.5 & 0.549 \\
\hline & Washroom & $\mathrm{BA}$ & A & VL & A & ExL & 0.41 & 0.5 & 0.255 & 0.5 & 0.135 & 0.360 \\
\hline & Maintenance & $\mathrm{H}$ & A & $\mathrm{H}$ & A & $\mathrm{H}$ & 0.665 & 0.5 & 0.665 & 0.5 & 0.665 & 0.599 \\
\hline & Management & $\mathrm{H}$ & $\mathrm{EH}$ & ExH & A & $\mathrm{L}$ & 0.665 & 0.955 & 0.865 & 0.5 & 0.335 & 0.664 \\
\hline & SRC & ExL & EL & ExL & ExL & EL & 0.135 & 0.045 & 0.135 & 0.135 & 0.045 & 0.099 \\
\hline \multirow{5}{*}{ Facility } & TV & EL & VL & EL & ExL & ExL & 0.045 & 0.255 & 0.045 & 0.135 & 0.135 & 0.123 \\
\hline & Laundry & VL & VL & $\mathrm{VL}$ & ExL & $\mathrm{VL}$ & 0.255 & 0.255 & 0.255 & 0.135 & 0.255 & 0.231 \\
\hline & ATM & ExL & VL & EL & ExL & ExL & 0.135 & 0.255 & 0.045 & 0.135 & 0.135 & 0.141 \\
\hline & Sports & $\mathrm{VL}$ & $\mathrm{BA}$ & $\mathrm{VL}$ & $\mathrm{L}$ & A & 0.255 & 0.41 & 0.255 & 0.335 & 0.5 & 0.351 \\
\hline & Study room & ExL & ExL & $\mathrm{VL}$ & EL & ExL & 0.135 & 0.135 & 0.255 & 0.045 & 0.135 & 0.141 \\
\hline \multirow{5}{*}{ Convenience } & Population & ExL & $\mathrm{L}$ & A & $\mathrm{L}$ & ExL & 0.135 & 0.335 & 0.5 & 0.335 & 0.135 & 0.288 \\
\hline & Size & $\mathrm{A}$ & $\mathrm{BA}$ & BA & A & $\mathrm{H}$ & 0.5 & 0.41 & 0.41 & 0.5 & 0.665 & 0.497 \\
\hline & Physical & VH & $\mathrm{H}$ & A & AA & $\mathrm{BA}$ & 0.745 & 0.665 & 0.5 & 0.59 & 0.41 & 0.582 \\
\hline & Lab & ExL & $\mathrm{L}$ & VL & $\mathrm{L}$ & VL & 0.135 & 0.335 & 0.255 & 0.335 & 0.255 & 0.263 \\
\hline & Wi-Fi & $\mathrm{H}$ & A & $\mathrm{A}$ & $\mathrm{H}$ & $\mathrm{H}$ & 0.665 & 0.5 & 0.5 & 0.665 & 0.665 & 0.599 \\
\hline \multirow{5}{*}{ Value for money } & Bus & ExH & A & AA & $\mathrm{BA}$ & A & 0.865 & 0.5 & 0.59 & 0.41 & 0.5 & 0.573 \\
\hline & Distance & $\mathrm{BA}$ & $\mathrm{BA}$ & $\mathrm{L}$ & $\mathrm{L}$ & A & 0.41 & 0.41 & 0.335 & 0.335 & 0.5 & 0.398 \\
\hline & Cafeteria & $\mathrm{H}$ & A & A & AA & A & 0.665 & 0.5 & 0.5 & 0.59 & 0.5 & 0.551 \\
\hline & Exterior & $\mathrm{L}$ & ExL & $\mathrm{AA}$ & AA & $\mathrm{BA}$ & 0.335 & 0.255 & 0.59 & 0.59 & 0.41 & 0.436 \\
\hline & Fees & $\mathrm{H}$ & $\mathrm{A}$ & $\mathrm{VH}$ & $\mathrm{H}$ & $\mathrm{AA}$ & 0.665 & 0.5 & 0.745 & 0.665 & 0.59 & 0.633 \\
\hline \multirow{2}{*}{ Precaution } & Security & $\mathrm{H}$ & $\mathrm{H}$ & AA & $\mathrm{A}$ & $\mathrm{AA}$ & 0.665 & 0.665 & 0.59 & 0.5 & 0.59 & 0.602 \\
\hline & Safety & $\mathrm{A}$ & $\mathrm{BA}$ & $\mathrm{L}$ & $\mathrm{L}$ & VL & 0.5 & 0.41 & 0.335 & 0.335 & 0.255 & 0.367 \\
\hline
\end{tabular}

the students to access the required information from any corners of the hostel and reduces the students' dependency on computer lab and also ensures them not to concern too much about the quality of the lab service.

According to the proposed model, the ranking of the residential halls based on global satisfaction score is as follows: $\mathrm{SME}>$ Petronas $>$ Bank Rakyat $>$ EON $>$ Perwaja $>$ $\mathrm{YAB}>$ Tradewinds $>\mathrm{TM}>\mathrm{TNB}>$ Muamalat $>$ Sime Darby $>$ Proton $>$ MAS $>$ MISC.

SME, Petronas, Bank Rakyat, EON, and Perwaja ruled the top five positions as they had satisfactory scores on service, facility, and convenience aspects which are the main determinants of students' satisfaction towards a hostel. Petronas has the potential to be in the top in the future if the hostel's administration put major effort on improving its service level by simultaneously enhancing the management and maintenance efficiency while retaining its performance in both facility and convenience aspects. Perwaja also has the opportunity to be in the lead if the administration simultaneously improves all the attributes within facility factor (TV, laundry, ATM, sports, and study room), regardless of their individual weights as they shared superadditive effect.
Tradewinds which obtained the lowest precaution score certainly can be in top 5 positions in future if the hostel tightens its security system and adds more safety equipment or features while maintaining its performance on service, facility, and convenience aspects.

Muamalat, Sime Darby, Proton, MAS, and MISC which are being at the bottom five positions attained poor scores mainly on service and facility aspects; thus, appropriate strategies should be planned to achieve perfection in these two aspects. They need to assure the management and maintenance doing their job effectively in fulfilling the students' needs. Besides, they should offer better TV, laundry, ATM, sports, and study room facilities to their students. However, it was discovered that MISC needs to take an extra effort where it should also focus on stepping up the precaution measures which can be achieved by simultaneously enhancing the existing security system and safety features.

The same evaluation is also carried out by only using the additive SWA operator and a different set of scores and ranking was obtained. This shows that neglecting interactions between hostel attributes could offer flawed information which consequently leads to wrong decisions. Therefore, 
TABLE 8: $\lambda$-measure weights for each factor.

\begin{tabular}{|c|c|c|c|c|c|c|c|}
\hline \multicolumn{2}{|c|}{ Service $(\lambda=-0.956)$} & \multicolumn{2}{|c|}{ Facility $(\lambda=0.035)$} & \multicolumn{2}{|c|}{ Convenience $(\lambda=-0.943)$} & \multicolumn{2}{|c|}{ Value for money $(\lambda=-0.972)$} \\
\hline Subsets & Weights & Subsets & Weights & Subsets & Weights & Subsets & Weights \\
\hline\{\} & 0.000 & \{\} & 0.000 & \{\} & 0.000 & \{\} & 0.000 \\
\hline$\left\{c_{11}\right\}$ & 0.549 & $\left\{c_{17}\right\}$ & 0.123 & $\left\{c_{4}\right\}$ & 0.288 & $\left\{c_{3}\right\}$ & 0.573 \\
\hline$\left\{c_{21}\right\}$ & 0.360 & $\left\{c_{18}\right\}$ & 0.231 & $\left\{c_{7}\right\}$ & 0.497 & $\left\{c_{2}\right\}$ & 0.398 \\
\hline$\left\{c_{11}, c_{21}\right\}$ & 0.720 & $\left\{c_{17}, c_{18}\right\}$ & 0.355 & $\left\{c_{4}, c_{7}\right\}$ & 0.650 & $\left\{c_{3}, c_{2}\right\}$ & 0.749 \\
\hline$\left\{c_{10}\right\}$ & 0.599 & $\left\{c_{16}\right\}$ & 0.141 & $\left\{c_{12}\right\}$ & 0.582 & $\left\{c_{9}\right\}$ & 0.551 \\
\hline$\left\{c_{11}, c_{10}\right\}$ & 0.834 & $\left\{c_{17}, c_{16}\right\}$ & 0.265 & $\left\{c_{4}, c_{12}\right\}$ & 0.712 & $\left\{c_{3}, c_{9}\right\}$ & 0.817 \\
\hline$\left\{c_{21}, c_{10}\right\}$ & 0.753 & $\left\{c_{18}, c_{16}\right\}$ & 0.373 & $\left\{c_{7}, c_{12}\right\}$ & 0.806 & $\left\{c_{2}, c_{9}\right\}$ & 0.736 \\
\hline$\left\{c_{11}, c_{21}, c_{10}\right\}$ & 0.907 & $\left\{c_{17}, c_{18}, c_{16}\right\}$ & 0.498 & $\left\{c_{4}, c_{7}, c_{12}\right\}$ & 0.875 & $\left\{c_{3}, c_{2}, c_{9}\right\}$ & 0.899 \\
\hline$\left\{c_{20}\right\}$ & 0.664 & $\left\{c_{19}\right\}$ & 0.351 & $\left\{c_{14}\right\}$ & 0.263 & $\left\{c_{1}\right\}$ & 0.436 \\
\hline$\left\{c_{11}, c_{20}\right\}$ & 0.865 & $\left\{c_{17}, c_{19}\right\}$ & 0.476 & $\left\{c_{4}, c_{14}\right\}$ & 0.480 & $\left\{c_{3}, c_{1}\right\}$ & 0.766 \\
\hline$\left\{c_{21}, c_{20}\right\}$ & 0.795 & $\left\{c_{18}, c_{19}\right\}$ & 0.585 & $\left\{c_{7}, c_{14}\right\}$ & 0.637 & $\left\{c_{2}, c_{1}\right\}$ & 0.665 \\
\hline$\left\{c_{11}, c_{21}, c_{20}\right\}$ & 0.927 & $\left\{c_{17}, c_{18}, c_{19}\right\}$ & 0.710 & $\left\{c_{4}, c_{7}, c_{14}\right\}$ & 0.752 & $\left\{c_{3}, c_{2}, c_{1}\right\}$ & 0.868 \\
\hline$\left\{c_{10}, c_{20}\right\}$ & 0.883 & $\left\{c_{16}, c_{19}\right\}$ & 0.494 & $\left\{c_{12}, c_{14}\right\}$ & 0.701 & $\left\{c_{9}, c_{1}\right\}$ & 0.753 \\
\hline$\left\{c_{11}, c_{10}, c_{20}\right\}$ & 0.968 & $\left\{c_{17}, c_{16}, c_{19}\right\}$ & 0.619 & $\left\{c_{4}, c_{12}, c_{14}\right\}$ & 0.798 & $\left\{c_{3}, c_{9}, c_{1}\right\}$ & 0.907 \\
\hline$\left\{c_{21}, c_{10}, c_{20}\right\}$ & 0.939 & $\left\{c_{18}, c_{16}, c_{19}\right\}$ & 0.729 & $\left\{c_{7}, c_{12}, c_{14}\right\}$ & 0.869 & $\left\{c_{2}, c_{9}, c_{1}\right\}$ & 0.860 \\
\hline$\left\{c_{11}, c_{21}, c_{10}, c_{20}\right\}$ & 0.995 & $\left\{c_{17}, c_{18}, c_{16}, c_{19}\right\}$ & 0.855 & $\left\{c_{4}, c_{7}, c_{12}, c_{14}\right\}$ & 0.921 & $\left\{c_{3}, c_{2}, c_{9}, c_{1}\right\}$ & 0.954 \\
\hline$\left\{c_{22}\right\}$ & 0.099 & $\left\{c_{15}\right\}$ & 0.141 & $\left\{c_{13}\right\}$ & 0.599 & $\left\{c_{8}\right\}$ & 0.633 \\
\hline$\left\{c_{11}, c_{22}\right\}$ & 0.596 & $\left\{c_{17}, c_{15}\right\}$ & 0.265 & $\left\{c_{4}, c_{13}\right\}$ & 0.724 & $\left\{c_{3}, c_{8}\right\}$ & 0.853 \\
\hline$\left\{c_{21}, c_{22}\right\}$ & 0.425 & $\left\{c_{18}, c_{15}\right\}$ & 0.373 & $\left\{c_{7}, c_{13}\right\}$ & 0.815 & $\left\{c_{2}, c_{8}\right\}$ & 0.786 \\
\hline$\left\{c_{11}, c_{21}, c_{22}\right\}$ & 0.751 & $\left\{c_{17}, c_{18}, c_{15}\right\}$ & 0.498 & $\left\{c_{4}, c_{7}, c_{13}\right\}$ & 0.882 & $\left\{c_{3}, c_{2}, c_{8}\right\}$ & 0.921 \\
\hline$\left\{c_{10}, c_{22}\right\}$ & 0.641 & $\left\{c_{16}, c_{15}\right\}$ & 0.283 & $\left\{c_{12}, c_{13}\right\}$ & 0.852 & $\left\{c_{9}, c_{8}\right\}$ & 0.845 \\
\hline$\left\{c_{11}, c_{10}, c_{22}\right\}$ & 0.854 & $\left\{c_{17}, c_{16}, c_{15}\right\}$ & 0.407 & $\left\{c_{4}, c_{12}, c_{13}\right\}$ & 0.909 & $\left\{c_{3}, c_{9}, c_{8}\right\}$ & 0.947 \\
\hline$\left\{c_{21}, c_{10}, c_{22}\right\}$ & 0.781 & $\left\{c_{18}, c_{16}, c_{15}\right\}$ & 0.516 & $\left\{c_{7}, c_{12}, c_{13}\right\}$ & 0.950 & $\left\{c_{2}, c_{9}, c_{8}\right\}$ & 0.916 \\
\hline$\left\{c_{11}, c_{21}, c_{10}, c_{22}\right\}$ & 0.920 & $\left\{c_{17}, c_{18}, c_{16}, c_{15}\right\}$ & 0.641 & $\left\{c_{4}, c_{7}, c_{12}, c_{13}\right\}$ & 0.980 & $\left\{c_{3}, c_{2}, c_{9}, c_{8}\right\}$ & 0.979 \\
\hline$\left\{c_{20}, c_{22}\right\}$ & 0.762 & $\left\{c_{19}, c_{15}\right\}$ & 0.494 & $\left\{c_{14}, c_{13}\right\}$ & 0.713 & $\left\{c_{1}, c_{8}\right\}$ & 0.801 \\
\hline$\left\{c_{11}, c_{20}, c_{22}\right\}$ & 0.882 & $\left\{c_{17}, c_{19}, c_{15}\right\}$ & 0.619 & $\left\{c_{4}, c_{14}, c_{13}\right\}$ & 0.808 & $\left\{c_{3}, c_{1}, c_{8}\right\}$ & 0.928 \\
\hline$\left\{c_{21}, c_{20}, c_{22}\right\}$ & 0.819 & $\left\{c_{18}, c_{19}, c_{15}\right\}$ & 0.729 & $\left\{c_{7}, c_{14}, c_{13}\right\}$ & 0.876 & $\left\{c_{2}, c_{1}, c_{8}\right\}$ & 0.889 \\
\hline$\left\{c_{11}, c_{21}, c_{20}, c_{22}\right\}$ & 0.938 & $\left\{c_{17}, c_{18}, c_{19}, c_{15}\right\}$ & 0.855 & $\left\{c_{4}, c_{7}, c_{14}, c_{13}\right\}$ & 0.926 & $\left\{c_{3}, c_{2}, c_{1}, c_{8}\right\}$ & 0.967 \\
\hline$\left\{c_{10}, c_{20}, c_{22}\right\}$ & 0.898 & $\left\{c_{16}, c_{19}, c_{15}\right\}$ & 0.637 & $\left\{c_{12}, c_{14}, c_{13}\right\}$ & 0.904 & $\left\{c_{9}, c_{1}, c_{8}\right\}$ & 0.923 \\
\hline$\left\{c_{11}, c_{10}, c_{20}, c_{22}\right\}$ & 0.976 & $\left\{c_{17}, c_{16}, c_{19}, c_{15}\right\}$ & 0.763 & $\left\{c_{4}, c_{12}, c_{14}, c_{13}\right\}$ & 0.946 & $\left\{c_{3}, c_{9}, c_{1}, c_{8}\right\}$ & 0.982 \\
\hline$\left\{c_{21}, c_{10}, c_{20}, c_{22}\right\}$ & 0.949 & $\left\{c_{18}, c_{16}, c_{19}, c_{15}\right\}$ & 0.873 & $\left\{c_{7}, c_{12}, c_{14}, c_{13}\right\}$ & 0.977 & $\left\{c_{2}, c_{9}, c_{1}, c_{8}\right\}$ & 0.964 \\
\hline$\left\{c_{11}, c_{21}, c_{10}, c_{20}, c_{22}\right\}$ & 1.000 & $\left\{c_{17}, c_{18}, c_{16}, c_{19}, c_{15}\right\}$ & 1.000 & $\left\{c_{4}, c_{7}, c_{12}, c_{14}, c_{13}\right\}$ & 1.000 & $\left\{c_{3}, c_{2}, c_{9}, c_{1}, c_{8}\right\}$ & 1.000 \\
\hline \multicolumn{8}{|c|}{ Safety $(\lambda=0.140)$} \\
\hline Subsets & Weights & & & & & & \\
\hline\{\} & 0.000 & & & & & & \\
\hline$\left\{c_{5}\right\}$ & 0.602 & & & & & & \\
\hline$\left\{c_{6}\right\}$ & 0.367 & & & & & & \\
\hline$\left\{c_{5}, c_{6}\right\}$ & 1.000 & & & & & & \\
\hline
\end{tabular}

TABLE 9: Fuzzy pairwise comparison matrix between hostel factors.

\begin{tabular}{lccccc}
\hline & Service & Facility & Convenience & Value for money & Precaution \\
\hline Service & $(1,1,1)$ & $(1,2,3)$ & $(2,3,4)$ & $(4,5,6)$ & $(3,4,5)$ \\
Facility & - & $(1,1,1)$ & $(1,2,3)$ & $(3,4,5)$ & $(2,3,4)$ \\
Convenience & - & - & $(1,1,1)$ & - & $(1,1,1)$ \\
Value for money & - & - & - & $(1,2,3)$ & $(1,2,3)$ \\
Precaution & - & & & - & $(1,1,1)$ \\
\hline
\end{tabular}


TABLE 10: Overall satisfaction score of each hostel and their ranking.

\begin{tabular}{lcccccc}
\hline Factors/hostels & $\begin{array}{c}\text { Service } \\
\left(w_{1}=0.374\right)\end{array}$ & $\begin{array}{c}\text { Facility } \\
\left(w_{2}=0.309\right)\end{array}$ & $\begin{array}{c}\text { Convenience } \\
\left(w_{3}=0.147\right)\end{array}$ & $\begin{array}{c}\text { Value for } \\
\text { money } \\
\left(w_{4}=0.065\right)\end{array}$ & $\begin{array}{c}\text { Precaution } \\
\left(w_{5}=0.106\right)\end{array}$ & Final scores \\
\hline Bank Rakyat & 5.337 & 4.870 & 6.105 & 4.991 & 5.044 & 5.257 \\
SME & 5.860 & 4.789 & 6.679 & 5.385 & 5.652 & 5.602 \\
Sime Darby & 4.751 & 3.765 & 5.981 & 5.373 & 4.663 & 4.663 \\
EON & 5.536 & 4.732 & 6.086 & 5.404 & 4.464 & 5.252 \\
Muamalat & 4.883 & 4.680 & 4.890 & 5.629 & 4.259 & 4.809 \\
YAB & 5.275 & 4.699 & 5.409 & 5.127 & 4.193 & 4.998 \\
Proton & 4.414 & 4.285 & 6.068 & 5.136 & 4.181 & 4 \\
MAS & 4.627 & 3.647 & 6.406 & 5.036 & 4.757 & 6 \\
Petronas & 5.091 & 5.479 & 6.261 & 5.867 & 4.962 & 4.631 \\
TNB & 5.091 & 3.764 & 5.998 & 5.437 & 4.899 & 5.425 \\
Tradewinds & 5.002 & 4.972 & 5.763 & 5.024 & 3.885 & 4.822 \\
Perwaja & 5.508 & 4.128 & 6.626 & 5.998 & 4.594 & 4.993 \\
MISC & 5.004 & 3.304 & 6.021 & 5.384 & 3.953 & 5.186 \\
TM & 5.159 & 4.008 & 6.651 & 5.247 & 4.302 & 4.546 \\
\hline
\end{tabular}

TABLE 11: Identification of additive weights of attributes for SWA operator.

\begin{tabular}{|c|c|c|c|c|}
\hline Factors & Attributes & Individual weights & Normalized weights & Final weights \\
\hline \multirow{6}{*}{ Service $(0.374)$} & Cleaning & 0.549 & 0.242 & 0.090 \\
\hline & Washroom & 0.360 & 0.159 & 0.059 \\
\hline & Maintenance & 0.599 & 0.264 & 0.099 \\
\hline & Management & 0.664 & 0.292 & 0.109 \\
\hline & SRC & 0.099 & 0.044 & 0.016 \\
\hline & SUM & 2.271 & 1.000 & \\
\hline \multirow{6}{*}{ Facility (0.309) } & $\mathrm{TV}$ & 0.123 & 0.125 & 0.039 \\
\hline & Laundry & 0.231 & 0.234 & 0.072 \\
\hline & ATM & 0.141 & 0.143 & 0.044 \\
\hline & Sports & 0.351 & 0.356 & 0.110 \\
\hline & Study room & 0.141 & 0.143 & 0.044 \\
\hline & SUM & 0.987 & 1.000 & \\
\hline \multirow{6}{*}{ Convenience (0.147) } & Population & 0.288 & 0.129 & 0.019 \\
\hline & Size & 0.497 & 0.223 & 0.033 \\
\hline & Physical & 0.582 & 0.261 & 0.038 \\
\hline & Lab & 0.263 & 0.118 & 0.017 \\
\hline & Wi-Fi & 0.599 & 0.269 & 0.039 \\
\hline & SUM & 2.229 & 1.000 & \\
\hline \multirow{6}{*}{ Value for money $(0.065)$} & Bus & 0.573 & 0.221 & 0.014 \\
\hline & Distance & 0.398 & 0.154 & 0.010 \\
\hline & Cafeteria & 0.551 & 0.213 & 0.014 \\
\hline & Exterior & 0.436 & 0.168 & 0.011 \\
\hline & Fees & 0.633 & 0.244 & 0.016 \\
\hline & SUM & 2.591 & 1.000 & \\
\hline \multirow{3}{*}{ Precaution (0.106) } & Security & 0.602 & 0.621 & 0.066 \\
\hline & Safety & 0.367 & 0.379 & 0.040 \\
\hline & SUM & 0.969 & 1.000 & \\
\hline SUM & & & & 1.000 \\
\hline
\end{tabular}


TABle 12: Proposed model versus classical SWA operator.

\begin{tabular}{lcccc}
\hline Hostels & \multicolumn{2}{c}{ Proposed model } & \multicolumn{2}{c}{ Classical SWA } \\
& Overall scores & Ranking & Overall scores \\
\hline Bank Rakyat & 5.257 & 3 & 5.024 & 5.369 \\
SME & 5.602 & 1 & 4.473 & 1 \\
Sime Darby & 4.663 & 11 & 5.098 & 11 \\
EON & 5.252 & 4 & 4.680 & 3 \\
Muamalat & 4.809 & 10 & 4.825 & 9 \\
YAB & 4.998 & 6 & 4.412 & 13 \\
Proton & 4.644 & 12 & 4.470 & 12 \\
MAS & 4.631 & 13 & 5.290 & 4 \\
Petronas & 5.425 & 2 & 4.595 & 10 \\
TNB & 4.822 & 9 & 4.821 \\
Tradewinds & 4.993 & 7 & 4.983 \\
Perwaja & 5.186 & 5 & 4.296 \\
MISC & 4.546 & 14 & 4.741 \\
TM & 4.943 & 8 & 7 \\
\hline
\end{tabular}

the proposed model is recommended in order to identify more practical ranking and to develop the optimal strategies for enhancing students' satisfaction towards each hostel as the hostel attributes are normally interacted to each other.

\section{Conclusion and Recommendation}

This paper has finally introduced a new hybrid MADM model which considers the interactions between hostel attributes while evaluating the students' satisfaction towards a set of hostels. The execution of the model can be simplified into following steps: identifying hostel evaluation attributes, data collection using simple random stratified sampling approach, constructing the performance matrix by averaging data on satisfaction, factor analyzing the data on importance of attributes to reduce the attributes into independent factors, exemplifying the evaluation problem via simpler hierarchical system diagram, identifying the interaction parameter and monotone measure within each factor, aggregating the interactive scores within each factor using Choquet integral, assigning weights on each independent factors using MFAHP, and finally the overall satisfaction score of each hostel is by aggregating the independent factor scores using SWA operator.

Apart from dealing with the interactions between attributes, the model is able to discover the main determinants of hostel satisfaction together with their weights and also reduces the actual number of $\lambda$-measure weights which need to be determined prior to using Choquet integral from $2^{n}$ to $\sum_{p=1}^{q} 2^{\left|f_{p}\right|}$ where $n$ represents the number of attributes, $f_{p}=\left(f_{1}, f_{1}, \ldots, f_{q}\right)$ represents the set of extracted factors, $q$ is the total number of factors, and $\left|f_{p}\right|$ denotes the number of attributes within factor, $p$.

The feasibility of the model was verified by carrying out a real evaluation problem involving fourteen UUM hostels where some potential strategies for enhancing the students' satisfaction towards certain hostels were proposed. The same hostel evaluation problem was assessed by only using the additive SWA operator which simply assumes independency between attributes and a different set of satisfaction scores and ranking of hostels were obtained. Therefore, it is advisable to use the proposed model for analyzing hostel satisfaction problem in order to identify more practical hostel rankings and to develop strategies with better efficiency for enhancing the students' satisfaction towards each hostel as in reality most of the hostels attributes hold interactive characteristics.

In future, besides analyzing students' satisfaction towards hostels, the proposed model can be also applied in other domains where the ranking of alternatives and the enhancement strategies need to be identified by considering multiple interactive attributes. However, the sampling approach may vary based on the objective of the evaluation problem or target population.

\section{Conflict of Interests}

The authors declare that there is no conflict of interests regarding the publication of this paper.

\section{Acknowledgments}

This research is supported by Ministry of Higher Education of Malaysia under Fundamental Research Grant Scheme (FRGS) with S/O Code, 11877, and Universiti Utara Malaysia through postgraduate incentive grant.

\section{References}

[1] H. Oppewal, Y. Poria, N. Ravenscroft, and G. Speller, "Student preferences for university accommodation: an application of the stated preference approach," in Housing, Space and Quality of Life, R. G. Mira, D. L. Uzzell, J. E. Real, and J. Romay, Eds., pp. 113-124, Ashgate Publishing, Surrey, UK, 2005.

[2] W. A. Astin, What Matters in College? Four Critical Years Revisited, Jossey-Bass, San Francisco, Calif, USA, 1993. 
[3] R. Moos and E. Lee, "Comparing residence hall and independent living settings," Research in Higher Education, vol. 11, no. 3, pp. 207-221, 1979.

[4] D. Amole, "Coping strategies for living in student residential facilities in Nigeria," Environment and Behavior, vol. 37, no. 2, pp. 201-219, 2005.

[5] R. M. Baron, D. R. Mandel, C. A. Adams, and L. M. Griffen, "Effects of social density in university residential environments," Journal of Personality and Social Psychology, vol. 34, no. 3, pp. 434-446, 1976.

[6] C. J. Holahan and B. L. Wilcox, "Residential satisfaction and friendship formation in high- and low-rise student housing: an interactional analysis," Journal of Educational Psychology, vol. 70, no. 2, pp. 237-241, 1978.

[7] N. B. A. Bakar and N. M. B. A. Bakart, "Students' satisfaction towards the university accommodation and public amenities," in Proceedings of the International Conference on Construction and Building Technology, Kuala Lumpur, Malaysia, June 2008.

[8] M. A. Hassanain, "On the performance evaluation of sustainable student housing facilities," Journal of Facilities Management, vol. 6, no. 3, pp. 212-225, 2008.

[9] D. Amole, "Residential satisfaction in students' housing," Journal of Environmental Psychology, vol. 29, no. 1, pp. 76-85, 2009.

[10] Y. Adewunmi, M. Omirin, F. Famuyiwa, and O. Farinloye, "Post-occupancy evaluation of postgraduate hostel facilities," Facilities, vol. 29, no. 3, pp. 149-168, 2011.

[11] F. Khozaei, N. Ayub, A. S. Hassan, and Z. Khozaei, "The factors predicting students' satisfaction with university hostels, case study, Universiti Sains Malaysia," Asian Culture and History, vol. 2, no. 2, pp. 148-158, 2010.

[12] N. U. Najib, N. A. Yusof, and Z. Osman, "Measuring satisfaction with student housing facilities," American Journal of Engineering and Applied Sciences, vol. 4, no. 1, pp. 52-60, 2011.

[13] J.-L. Marichal, "An axiomatic approach of the discrete Choquet integral as a tool to aggregate interacting criteria," IEEE Transactions on Fuzzy Systems, vol. 8, no. 6, pp. 800-807, 2000.

[14] C. L. Hwang and K. Yoon, "Introduction," in Multiple Attribute Decision Making, vol. 186 of Lecture Notes in Economics and Mathematical Systems, pp. 1-15, Springer, Berlin, Germany, 1981.

[15] S. Mussi, "Facilitating the use of multi-attribute utility theory in expert systems: an aid for identifying the right relative importance weights of attributes," Expert Systems, vol. 16, no. 2, pp. 87-1102, 1999.

[16] E. Triantaphyllou, Multi-Criteria Decision Making Methodologies: A Comparative Study, vol. 44 of Applied Optimization, Kluwer Academic Publishers, 2000.

[17] E. U. Choo, B. Schoner, and W. C. Wedley, "Interpretation of criteria weights in multicriteria decision making," Computers \& Industrial Engineering, vol. 37, no. 3, pp. 527-541, 1999.

[18] J.-L. Marichal, Aggregation operator for multicriteria decision aid [Ph.D. thesis], University of Liege, Liège, Belgium, 1999.

[19] M. Detyniecki, Mathematical aggregation operators and their application to video querying [Ph.D. thesis], University of Paris VI, Paris, France, 2000.

[20] H. Bendjenna, P.-J. Charre, and N. E. Zarour, "Using multicriteria analysis to prioritize stakeholders," Journal of Systems and Information Technology, vol. 14, no. 3, pp. 264-280, 2012.

[21] D. Ralescu and G. Adams, "The fuzzy integral," Journal of Mathematical Analysis and Applications, vol. 75, no. 2, pp. 562$570,1980$.
[22] G.-H. Tzeng, Y.-P. Ou Yang, C.-T. Lin, and C.-B. Chen, "Hierarchical MADM with fuzzy integral for evaluating enterprise intranet web sites," Information Sciences, vol. 169, no. 3-4, pp. 409-426, 2005.

[23] G. Choquet, “Theory of capacities," Annales de l'Institut Fourier, vol. 5, pp. 131-295, 1953.

[24] M. Grabisch, "Fuzzy integral in multicriteria decision making," Fuzzy Sets and Systems, vol. 69, no. 3, pp. 279-298, 1995.

[25] M. Grabisch, "Fuzzy integral as a flexible and interpretable tool of aggregation," in Aggregation and Fusion of Imperfect Information, B. Bouchon-Meunier, Ed., vol. 12 of Stud. Fuzziness Soft Comput., pp. 51-72, Physica, Heidelberg, Germany, 1998.

[26] M. Grabisch and M. Roubens, "Application of the Choquet integral in multicriteria decision making," in Fuzzy Measures and Integrals: Theory and Applications, M. Grabisch, T. Murofushi, and M. Sugeno, Eds., pp. 415-434, Physica, Berlin, Germany, 2000.

[27] S. Angilella, S. Greco, F. Lamantia, and B. Matarazzo, "Assessing non-additive utility for multicriteria decision aid," European Journal of Operational Research, vol. 158, no. 3, pp. 734-744, 2004.

[28] G. Beliakov and S. James, "Citation-based journal ranks: the use of fuzzy measures," Fuzzy Sets and Systems, vol. 167, no. 1, pp. 101-119, 2011.

[29] I. Kojadinovic, "Estimation of the weights of interacting criteria from the set of profiles by means of information-theoretic functionals," European Journal of Operational Research, vol. 155, no. 3, pp. 741-751, 2004.

[30] P. Meyer and M. Roubens, "On the use of the Choquet integral with fuzzy numbers in multiple criteria decision support," Fuzzy Sets and Systems, vol. 157, no. 7, pp. 927-938, 2006.

[31] M. Sugeno, Theory of fuzzy integrals and its applications [Ph.D. thesis], Tokyo Institute of Technology, Tokyo, Japan, 1974.

[32] K. Ishii and M. Sugeno, "A model of human evaluation process using fuzzy measure," International Journal of Man-Machine Studies, vol. 22, no. 1, pp. 19-38, 1985.

[33] Y.-C. Hu and H. Chen, "Choquet integral-based hierarchical networks for evaluating customer service perceptions on fast food stores," Expert Systems with Applications, vol. 37, no. 12, pp. 7880-7887, 2010.

[34] T. Gürbüz, S. E. Alptekin, and G. Işiklar Alptekin, "A hybrid MCDM methodology for ERP selection problem with interacting criteria," Decision Support Systems, vol. 54, no. 1, pp. 206214, 2012.

[35] T. Murofushi and M. Sugeno, "An interpretation of fuzzy measures and the Choquet integral as an integral with respect to a fuzzy measure," Fuzzy Sets and Systems, vol. 29, no. 2, pp. 201-227, 1989.

[36] S. J. Chen and C. L. Hwang, "Fuzzy multiple attribute decision making methods," in Fuzzy Multiple Attribute Decision Making-Methods and Applications, vol. 375 of Lecture Notes in Economics and Mathematical Systems, pp. 289-486, Springer, 1992.

[37] L. Mikhailov, "Deriving priorities from fuzzy pairwise comparison judgements," Fuzzy Sets and Systems, vol. 134, no. 3, pp. 365385, 2003. 


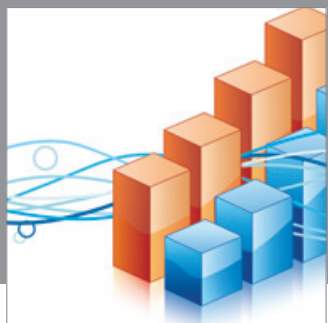

Advances in

Operations Research

mansans

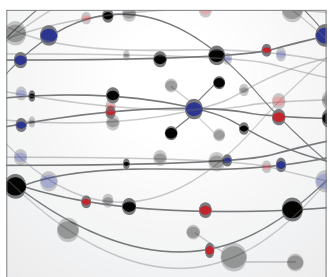

The Scientific World Journal
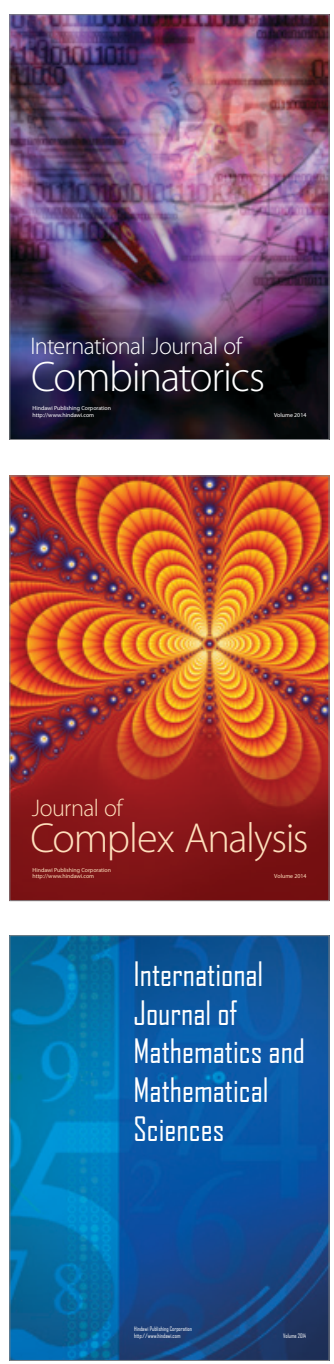
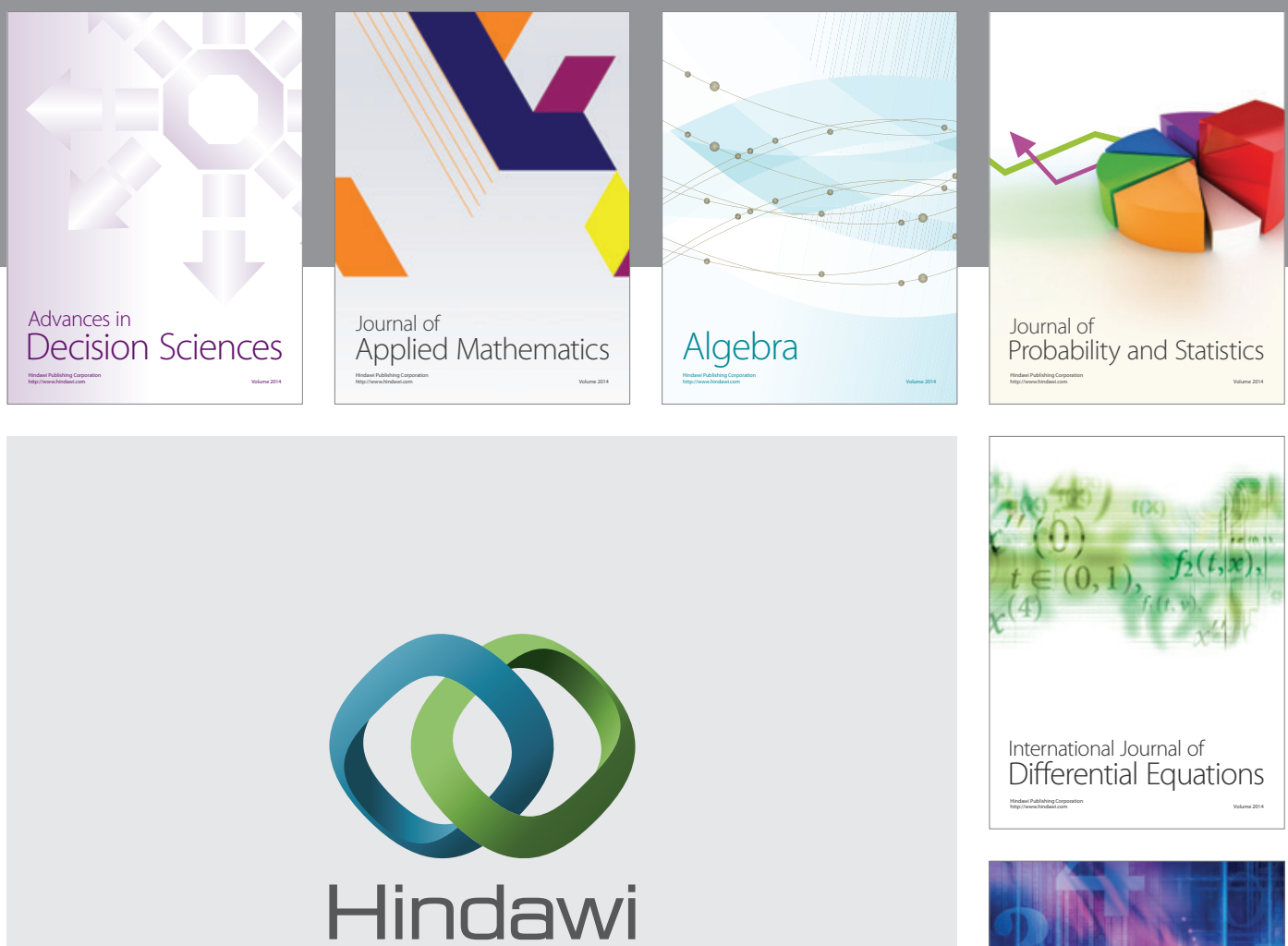

Submit your manuscripts at http://www.hindawi.com
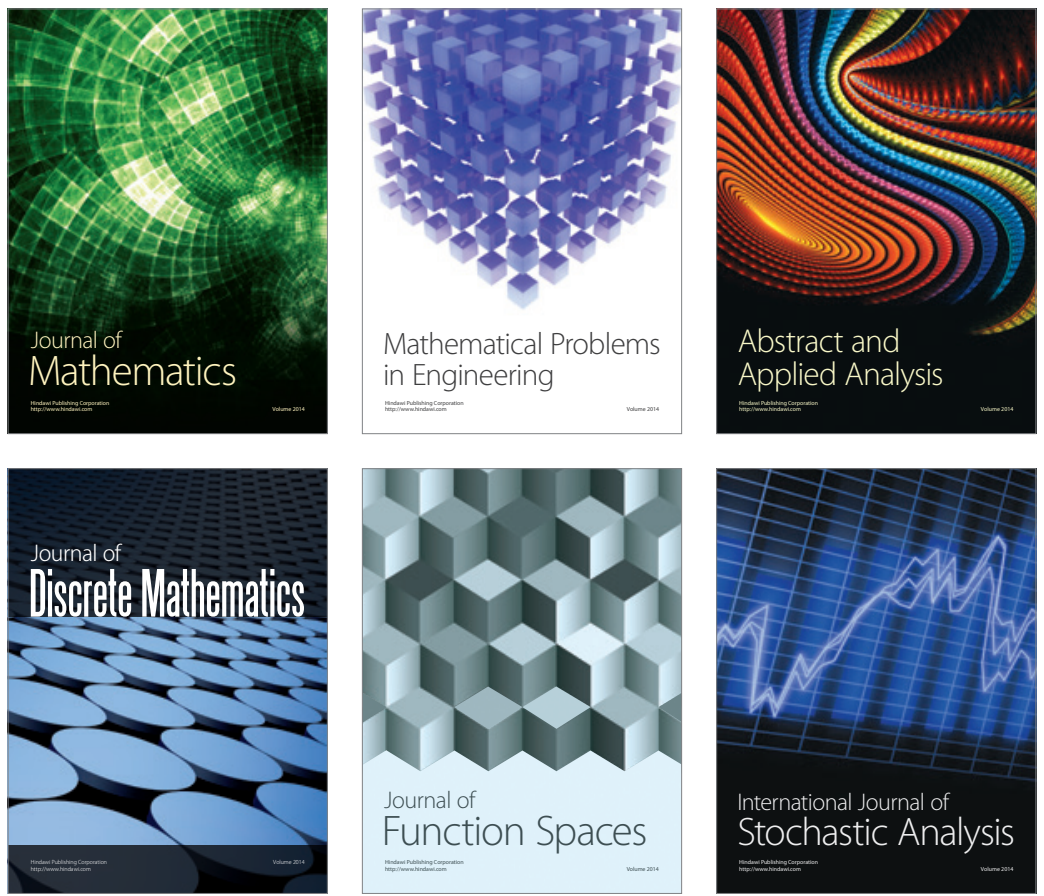

Journal of

Function Spaces

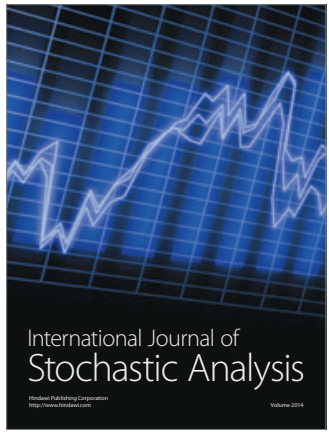

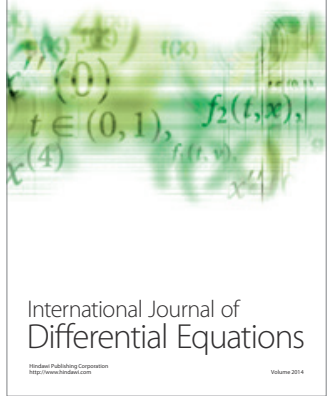
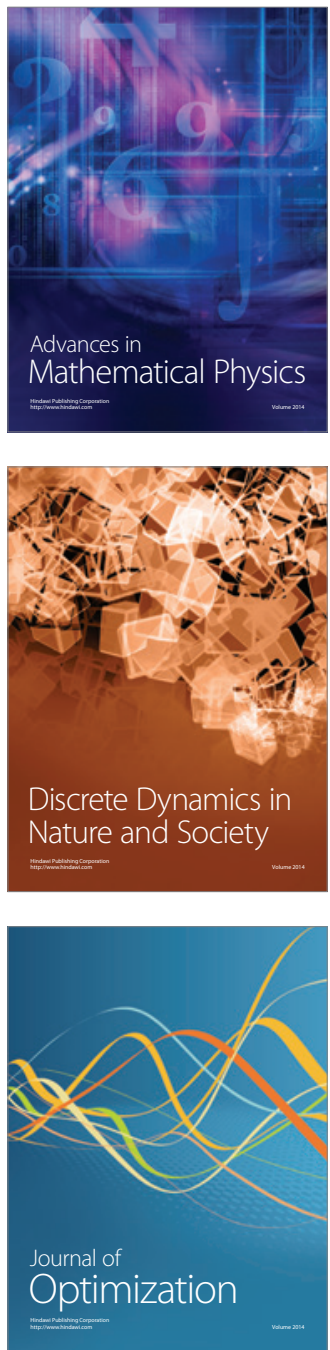